\title{
Effect of various media and supplements on laccase activity and its application in dyes decolorization
}

\author{
${ }^{*}$ Abeer, Abas. Abd El Aty and Faten, Ahmed. Ali \\ Chemistry of Natural and Microbial Products Dept. National Research Centre, Cairo, Egypt. \\ Email: aabass44@yahoo.com
}

Received 7 October 2012; Received in revised form 13 December 2012; Accepted 14 December 2012

\begin{abstract}
Aims: Marine-derived fungi are a potential for the search of new compounds with relevant features. Among these, the ligninolytic enzymes have potential applications in a large number of fields, including the environmental and industrial sectors. This work aimed to evaluate the laccase activity of the marine-derived fungus Alternaria alternata, under various cultivation conditions and its application in synthetic dyes decolorization.

Methodology and results: Wheat bran prepared with $40 \mathrm{~mL}$ sea water proportion was the most suitable substrate for laccase production $(114.06 \pm 2.24 \mathrm{U} / \mathrm{mL})$ by $A$. alternata, after 14 days of incubation in submerged fermentation. Laccase production in static cultivation was superior to that in agitated cultures. The simple Boyd and Kohlmeyer medium with supplementation of $2 \mathrm{mM}$ CuSO $4.5 \mathrm{H}_{2} \mathrm{O}$ on day 6 , at an incubation period of 14 days and incubation temperature of $28 \pm 2{ }^{\circ} \mathrm{C}$ under static conditions, yielded amounts of laccase $(36.13 \pm 0.34 \mathrm{U} / \mathrm{mL})$ less than that obtained with submerged fermentation of wheat bran as unique substrate. Furthermore, A. alternata has high decolorization capability toward azo dyes in the absence of redox mediators, $75.47 \%$ of the Reactive Black at $0.01 \%$ concentration, was removed after 30 days of incubation. Also has good ability to decolorize the triphenylmethane dye Crystal Violet, at $0.01 \%$ concentration, about $69.35 \%$ of the dye was removed after 30 days.
\end{abstract}

Conclusion, Significance and Impact of study: These unusual properties demonstrate that the marine-derived fungus Alternaria alternata has potentials in specific industrial or environmental applications.

Keywords: marine-derived fungi, laccase, agricultural wastes, inducers, decolorization.

\section{INTRODUCTION}

Laccases (1.10.3.2, p-diphenol: dioxygen oxidoreductases), along with manganese peroxidase and lignin peroxidase, are a type of lignin-modifying enzyme (LME). Laccases have a wide substrate range, which can serve industrial purposes and/or bioremediation processes. The simple requirements of laccase catalysis (presence of substrate and $\mathrm{O}_{2}$ ), as well as its apparent stability and lack of inhibition (as has been observed with $\mathrm{H}_{2} \mathrm{O}_{2}$ for peroxidase), make this enzyme both suitable and attractive for biotechnological applications (Majeau et al., 2010).

Fungi have been isolated and enumerated from mangrove leaves, seagrasses and salt marsh grass (Sathe and Raghukumar, 1991; Newell, 1993; Raghukumar et al., 1995). Several reports have demonstrated active loss in weight of various timber blocks colonized by marine wood-degrading fungi (Nilsson et al., 1989; Pointing et al., 1998; Pointing and Hyde, 2000; Bucher et al., 2004). Interestingly, most of these reported fungi belong to ascomycetes and a very few to basidiomycetes or white-rot fungi. Enumeration of fungi, their succession and decomposition of mangrove wood is reported from various tropical and subtropical parts of the world by numerous workers (Vrijmoed and Tan, 1990; Chinnaraj and Untawale, 1992; Vishwakiran et al., 2001). Therefore, fungi growing under such marine conditions are expected to have adapted to grow under saline (ranging from 10-34 ppt) and alkaline conditions since the $\mathrm{pH}$ of seawater ranges from 7.5 to 8.2. Such LDE-producing fungi should find application in bioremediation of lignin-based derivatives in colored industrial pollutants such as paper and pulp mills, tanneries, molasses-based distilleries and textile mills. These effluents are mostly alkaline and have high salt content (Bartlett, 1971) and therefore, marine fungi, facultative or obligate that grow in the presence of saline and alkaline conditions perhaps are well suited for treatment of such effluents.

The present study was undertaken to explore the laccase production ability of the filamentous marinederived fungus Alternaria alternata under different nutritional conditions. Also describe the effect of addition of different supplements on laccase production and optimization. The ability of the fungus to decolorize the

\section{${ }^{\star}$ Corresponding author}


synthetic dyes: Reactive Black, Malachite Green and Crystal Violet were also studied.

\section{MATERIALS AND METHODS}

\section{Chemicals}

2-Methoxyphenol (Guaiacol) was purchased from SigmaAldrich, Pf, D-89555 Steinheim, 07323/970, China. 2,2'Azino-bis(3-ethylbenzothiazoline-6-sulphonic acid) diammonium salt (ABTS) was obtained from MP Biomedicals, LLC.29525 Fountain Pkwy, Solon, OH 44139,USA. Reactive Black, Malachite Green and Crystal Violet were purchased from Sigma Company, Germany.

\section{Marine-derived filamentous fungi}

Decayed wood pieces of old fishing boats from Ismalia, Egypt were collected in sterile plastic bags. They were washed free of attached soil particles and other extraneous matter using sterile sea water. The wood pieces were then blotted between two folds of sterilized filter paper and transferred to petri dishes contained Boyd and Kohlmeyer (B \& K) agar ( $\mathrm{g} / \mathrm{L})$ (glucose 10, peptone 2, yeast extract 1 , agar 18 in $1 \mathrm{~L}$ of $50 \%$ sea water). As soon as fungal mycelia were observed to colonize the wood pieces the fungal mycelia were picked up and transferred to B\&K agar slants. The same medium was used for maintenance of the cultures in the refrigerator at $\left(5-6{ }^{\circ} \mathrm{C}\right)$ for later use (D'Souza et al., 2006).

Isolated fungi were identified in the National Research Centre, Chemistry of Natural and Microbial Products Dept. [Microbial Culture Collection Unit (MCCU)] according to (Pitt and Hocking, 1985; Kohlmeyer and Kohlmeyer, 1991) which depends on the descriptions of the morphology of the fungus.

\section{Qualitative assay for laccase activity}

The isolates were screened for laccase production by growing them on plates of $B \& K$ medium containing $4 \mathrm{mM}$ guaiacol (D'Souza et al., 2006). The production of an intense brown color under and around the fungal colony resulting from guaiacol oxidation was considered as a positive reaction for the presence of laccase activity (Okino et al., 2000).

\section{Inoculum preparation}

Two disks $7 \mathrm{~mm}$ in diameter from 7 days old cultures grown on malt extract agar medium (g/L) (biomalt 20 , agar $15,800 \mathrm{~mL}$ sterile sea water and $200 \mathrm{~mL}$ distilled water) were used to inoculate $50 \mathrm{~mL}$ of sterile medium in $250 \mathrm{~mL}$ Erlenmeyer flask (Höller, 1999).

\section{Medium and cultural conditions for submerged fermentation (SMF)}

Various agro industrial residues like corn cobs, wheat bran, wheat straw, rice straw and saw dust (each $3 g / 250$
$\mathrm{mL}$ Erlenmeyer flask with $50 \mathrm{~mL}$ sea water under static conditions) were screened for the production of laccase in submerged fermentation. Incubation was carried out at $28 \pm 2{ }^{\circ} \mathrm{C}$ for 2 weeks

\section{Factors affecting laccase activity}

Agitation rate (150-200 rpm) and different sea water proportions $(5,10,20,30,40$ and $50 \mathrm{~mL})$ were also varied to study their influence on laccase production.

The effect of additives was evaluated by adding the tested additives at the following concentrations $(\mathrm{g} / \mathrm{L})$ : malt extract (30), peptone (20) and $\mathrm{CuSO}_{4} \cdot 5 \mathrm{H}_{2} \mathrm{O}(3 \mathrm{mM})$ (Levin et al., 2008).

\section{Effect of inducers}

In order to study the effect of inducers on enzyme production, as another fermentation medium for laccase production. various inducers like guaiacol (1 mM), 2,2'Azino-bis(3-ethylbenzothiazoline-6-sulphonic acid) diammonium salt (ABTS) $(1 \mathrm{mM})$ and copper sulphate $(2$ $\mathrm{mM}$ ) were added on day 6 to stationary cultures grown in $50 \mathrm{~mL}$ of $\mathrm{B} \& \mathrm{~K}$ broth. The basal medium contained $(\mathrm{g} / \mathrm{L})$ (glucose 10 , peptone 2 , yeast extract 1 , in $1 \mathrm{~L}$ of $50 \%$ sea water) at $28 \pm 2{ }^{\circ} \mathrm{C}$ to determine laccase activity over a period of 21 days (D'Souza et al., 2006). Control flasks were supplied with basal medium without any inducers.

The culture growth was filtered on days $(3,7,10,14$, 17 and 21) to separate the mycelium from the culture medium in which the enzyme activity was evaluated. Values shown are the mean of duplicate cultivation experiments.

\section{Enzyme assay}

Laccase (EC 1.10.3.2) activity was measured by using the method described by Bournnais et al. (1995) based on the oxidation of the substrate 2,2'-azino-bis (3ethylbenzothiazoline)-6-sulphonic acid (ABTS). The rate of ABTS oxidation was determined spectrophotometrically at $420 \mathrm{~nm}$.

The reaction mixture contained $600 \mu \mathrm{L}$ sodium acetate buffer $\left(0.1 \mathrm{M}, \mathrm{pH} 5.0\right.$ at $\left.27^{\circ} \mathrm{C}\right), 300 \mu \mathrm{L}$ ABTS $(5$ $\mathrm{mM}), 300 \mu \mathrm{L}$ mycelial liquid fraction and $1400 \mu \mathrm{L}$ distilled water. The mixture was then incubated for $2 \mathrm{~min}$ at $30^{\circ} \mathrm{C}$. The absorbance was measured immediately in oneminute intervals. One unit of laccase activity was defined as activity of an enzyme that catalyzes the conversion of 1 mole of ABTS ( $\left.\varepsilon_{420}=36,000 / \mathrm{M} . \mathrm{cm}\right)$ per $\min$

The blank contained all the assay constituents except the active enzyme; heated inactivated enzyme was used in its place.

\section{Dye decolourization studies}

The decolorization studies were carried out in liquid malt extract (ME) medium containing (malt extract $1 \%$ and glucose 1\%) (Eichlerovà et al., 2006) and supplemented 
with the tested dyes (Reactive Black, Malachite Green and Crystal Violet) at final concentrations of $0.05 \%$ and $0.01 \%$. Fungal mycelia (2 discs $10 \mathrm{~mm}$ diameter) were inoculated into the $250 \mathrm{~mL}$ flask (working volume $50 \mathrm{~mL}$ ) and the reaction mixture was incubated at $30{ }^{\circ} \mathrm{C}$ under gently shaken $(60 \mathrm{rpm})$ in rotary shaker for 30 days.

Decolorization was measured in the filtrate after removing the mycelia and monitored spectrophotometrically at the maximum visible wavelength of absorbance (480 for Reactive Black, 620 for Malachite Green and 560 for Crystal Violet). Color removal was reported as \% decolorization $=\left(A_{i}-A_{t}\right) / A_{i} \times$ 100. Where $A_{i}$ is the initial absorbance before incubation and $A_{t}$ is the absorbance after incubation time $(4,7,10$, 13, 19, 26, 30 days) (Mtui and Nakamura, 2008).

\section{RESULTS AND DISCUSSION}

\section{Marine-derived fungi isolation and identification}

The marine-derived fungus showed a halo of intense brown color under and around the colony (Positive for guaiacol oxidation) was identified as $A$. alternata, according to their morphological characters. The fungal colony has olivaceous-black color. Conidiophores 1-3 septate, simple or sometimes branched, straight or flexuous, medium brown, smooth walled. Conidia is long often branched chains, obclavate, obpyriform, sometimes ovoid or ellipsoidal, often with a short conical or cylindrical beak, with up to 8 transverse and several longitudinal septa, pale to medium brown, smooth walled or verrucose.

Qualitative assay for all the marine-derived fungi isolated from decayed wood pieces indicated that the fungus $A$. alternata was the most promising for laccase enzyme production and used for the present work Figure 1. The ability of $A$. alternata enzymes to degrade the aromatic model compound indicated that they are the main decomposers of cellulose, hemicellulose and lignin contained in the wood samples; this implies that the enzymes can also be used in detoxification of aromatic pollutants such as agrochemicals and industrial effluents.

Mtui and Masalu (2008) demonstrated the guaiacol oxidation by mycelial cultures of a marine fungal isolate Laetiporus sulphureus isolated from mangrove forests of coastal Tanzania after 7 days of incubation.

\section{Production of laccase enzyme under various cultivation conditions}

In order to select the best medium for laccase production, two different fermentation media were tested.

\section{Laccase production in agricultural residues- containing medium}

Results presented in Figure 2 showed that, among the different agro industrial residues screened for laccase production, wheat bran was the most suitable substrate

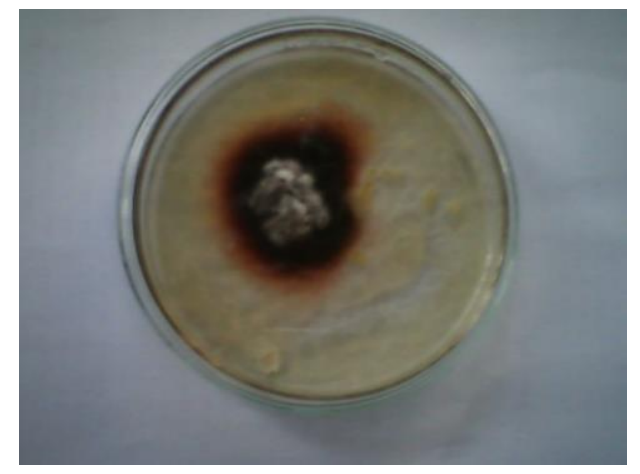

Figure 1: Photo of B\&K agar plate showing a halo of intense brown color formed under and around the marine derived A. alternata colony (Positive for guaiacol oxidation).

for laccase production $(77.50 \pm 1.07 \mathrm{U} / \mathrm{mL})$ by $A$. alternata after 14 days of incubation in submerged fermentation. Corn cobs, rice straw and potato shell were also identified as promising substrates while the production in other substrates like wheat straw and saw dust were very low, these results lind with Galliano et al. (1991) and Maltseva et al. (1991) who reported the production of laccase and Mn-dependent peroxidase by Rigidoporus lignosus and Panus tigrinus, respectively, in sawdust and wheat straw medium.

\section{Laccase production in B\&K medium with different inducers.}

The nature of the compound that induces laccase activity differs greatly with the species (Leonowicz et al., 2001; De Souza et al., 2004).

The results of our studies on three different putative inducers of laccase, ABTS, guaiacol and copper sulphate indicated that copper sulphate was the most suitable inducer for laccase production by $A$. alternata $(36.13 \pm 0.34$ $\mathrm{U} / \mathrm{mL}$ ), after 14 days of incubation as similar to that in most of the fungi (Palmieri et al., 2000; Galhaup and Haltrich, 2001).

The phenolic compound guaiacol $(8.18 \pm 0.26 \mathrm{U} / \mathrm{mL})$ also proved to be a promising inducer for laccase production by this strain. Addition of non-phenolic heterocyclic ABTS showed less effect on laccase production $(4.6 \pm 0.24 \mathrm{U} / \mathrm{mL})$ compared to the control experiment without inducers Figure 3 .

Static submerged wheat bran medium showed the ability of $A$. alternata to produce appreciable amount of laccase after 14 days of addition better than using B\&K medium supplemented with copper sulphate $(2 \mathrm{mM})$. This medium was then used for optimization of the production of laccase.

\section{Effect of agitation rate (rpm)}

Results in Figure 4 showed less amounts of laccase activity in all shaken cultures, the highest laccase activity 


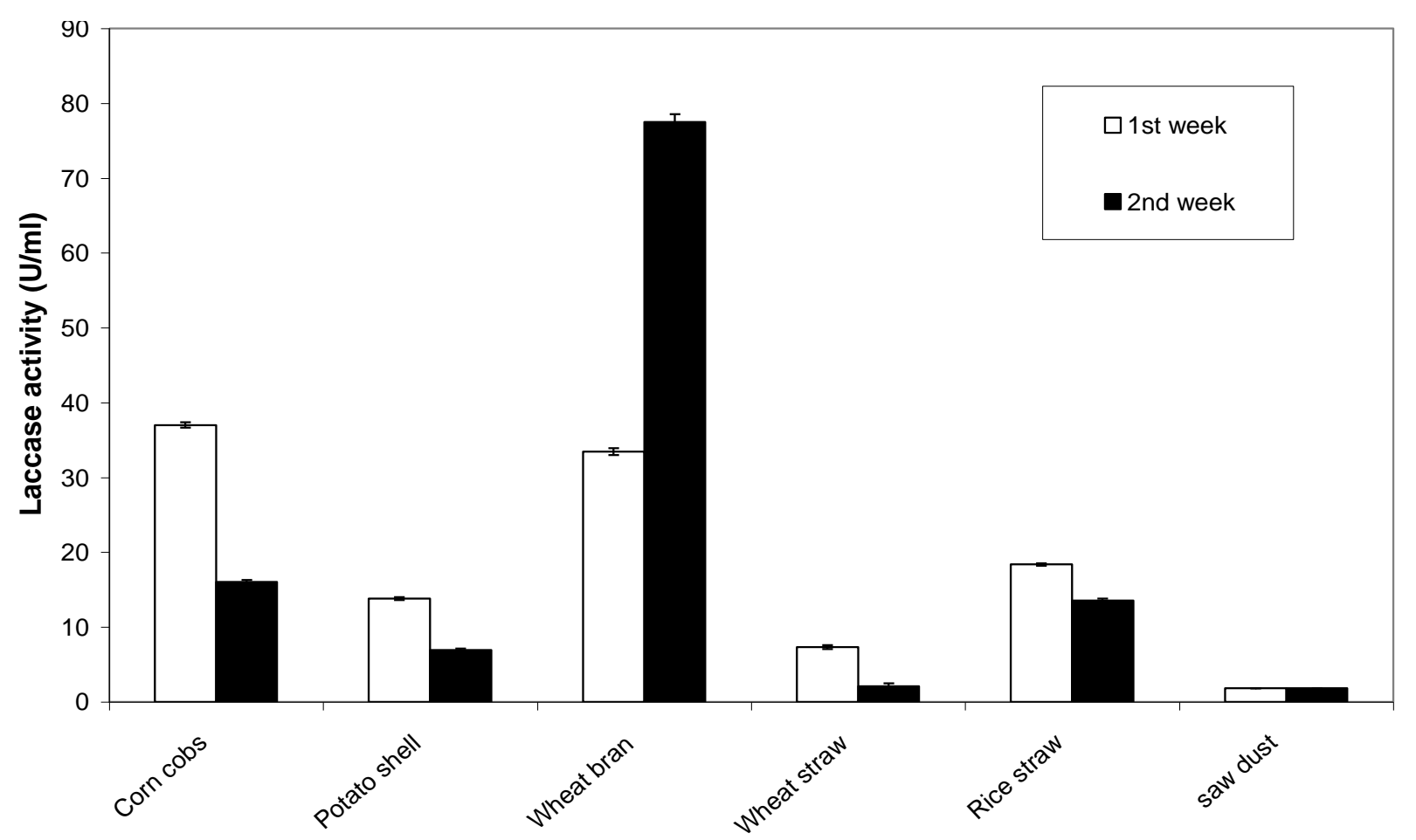

Lignocellulosic substrates

Figure 2: Production of laccase enzyme by the marine-derived fungus $A$. alternata on different lignocellulosic substrates in submerged fermentation, under static condition and incubation temperature $28 \pm 2{ }^{\circ} \mathrm{C}$.

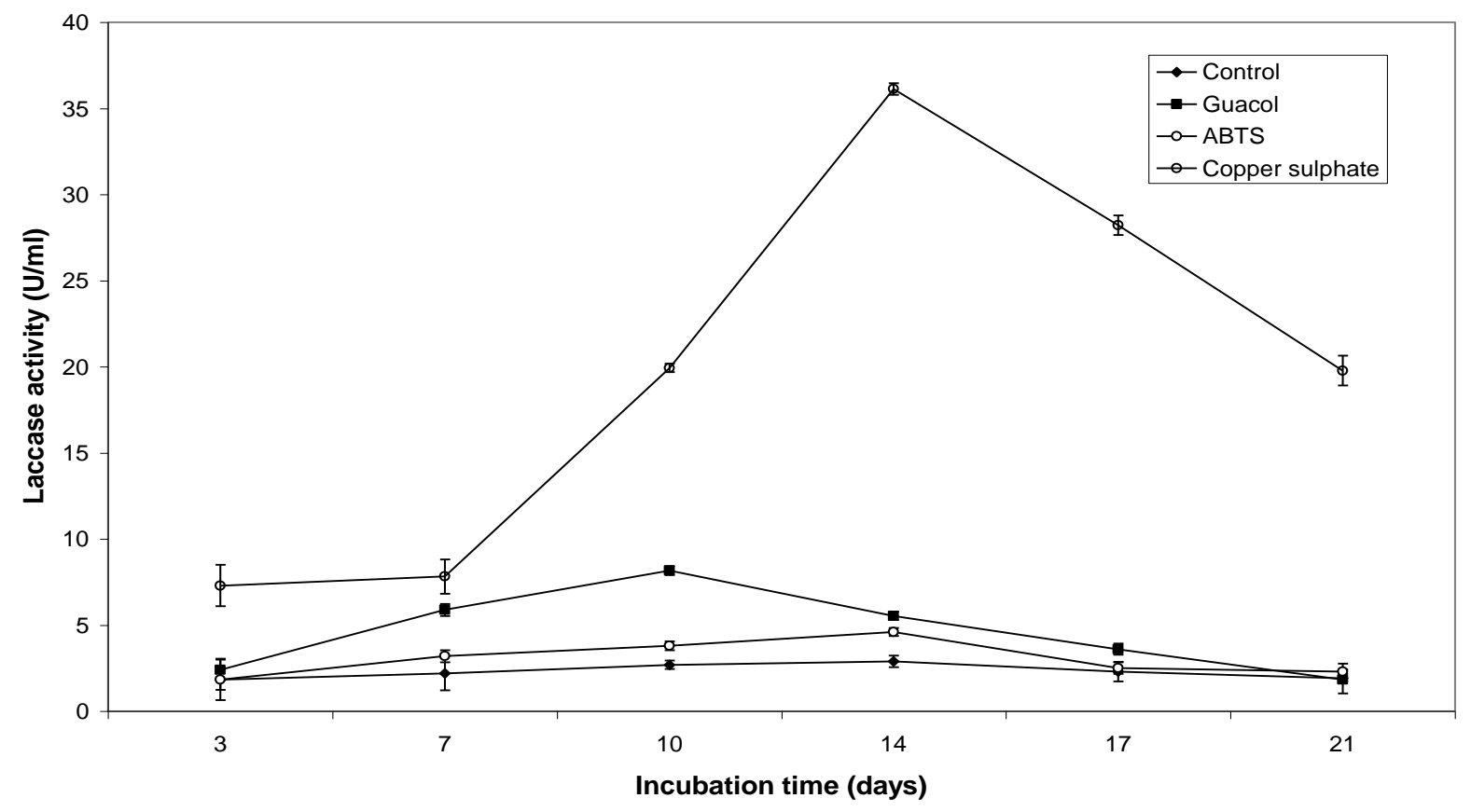

Figure 3: Effect of different inducers (added after 6 days of incubation) on laccase production by $A$. alternata when grown in static culture. Values shown are the mean of duplicate cultivation experiments and error bars represent SD. 


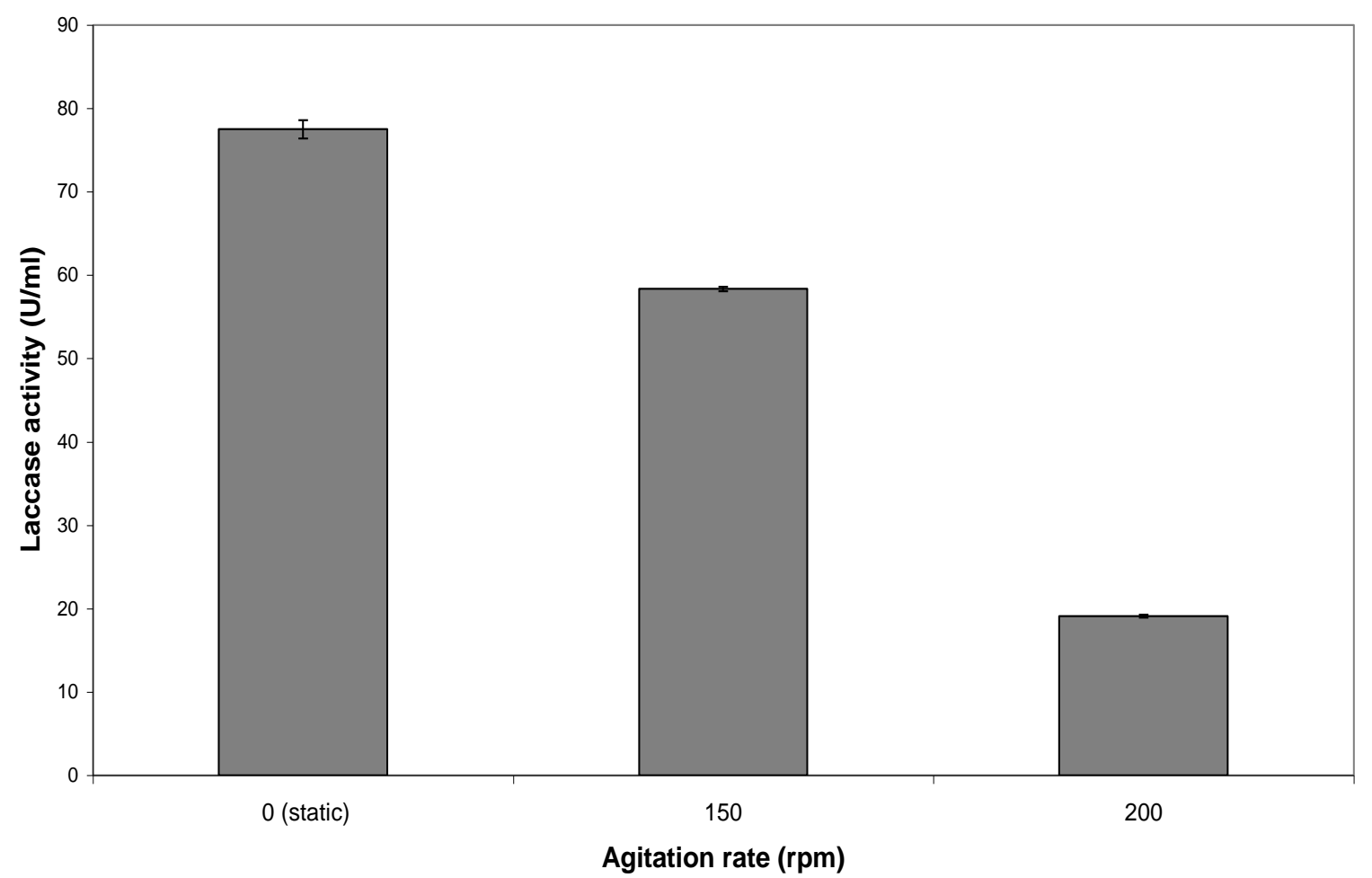

Figure 4: Effect of agitation rate (rpm) on laccase enzyme production in submerged fermentation of wheat bran after 14 days compared to the incubation under static conditions.

(77.50 $\pm 1.07 \mathrm{U} / \mathrm{mL})$ was obtained at static conditions and increasing the rate of shaking resulted in reverse result in laccase yield. At 150 and $200 \mathrm{rpm}$ the yield decreased 1.33 and 4.06 fold, respectively than that of static culture (control). This drop in enzyme yield in well-agitated flasks could be attributed to the possible damage that may occur in the filamentous structure of the organism and thus hindering the enzyme production. This explanation agrees with that of Robles et al. (2002) who found that the culture agitation of Chalara (syn. Thielaviopsis) paradoxa $\mathrm{CH} 32$ resulted in faster growth and earlier laccase production. For this, static cultures were used in the following experiments.

\section{Production of laccase in different media of wheat bran with other additives}

The effect of different additives was evaluated, results shown in Figure 5 Indicated that the enzyme exhibited different responses in the diverse media assayed. When using wheat straw, as unique substrate, $A$. alternata produced the highest level of laccase activity, when malt extract and peptone were added to the media the titers of laccase were very low $(16.60 \pm 1.37$ and $11.71 \pm 1.49 \mathrm{U} / \mathrm{mL}$, respectively), where maximum fungal growth was obtained. Arora and Gill (2001) indicated that malt extract broth increased the production of laccase in phlebia raiata and phlebia fascicularia. Other study of (Galhaup et al.,
2002) showed that the complex organic $N$ source, peptone from meat was the best for laccase production by Trametes pubescens.

Also addition of cooper sulphate in combination with malt extract and peptone decreased the activity and the fungal growth. This drop in enzyme yield probably due to a toxic effect on the fungal culture, and this high concentration of copper is a potent inhibitor of fungal growth as well as enzyme production. These results agreed with Baldrian (2003) who found that $\mathrm{Cu}^{2+}$ inhibited the growth of Ganoderma lucidum at concentrations less than $1 \mathrm{mM}$, while $150 \mathrm{ppm}$ of $\mathrm{Cu}^{2+}$ decreased the growth rate of $P$. crysosporium. Also $1.6 \mathrm{mM} \mathrm{Cu}^{2+}$ reduced the growth of $T$. trogii in submerged fermentation (Levin et al., 2002).

\section{Effect of different sea water proportion on laccase production}

Varying amounts of water in the fermentation media considered an important factor affecting the fungal growth and enzymes production.

Results in Figure 6 showed that laccase activity increased as sea water proportion increased until reached maximum $(114.06 \pm 2.24 \mathrm{U} / \mathrm{mL})$ with $40 \mathrm{~mL}$ sea water proportion where the activity increased about 1.47 fold compared to the control medium prepared with $50 \mathrm{~mL}$. 


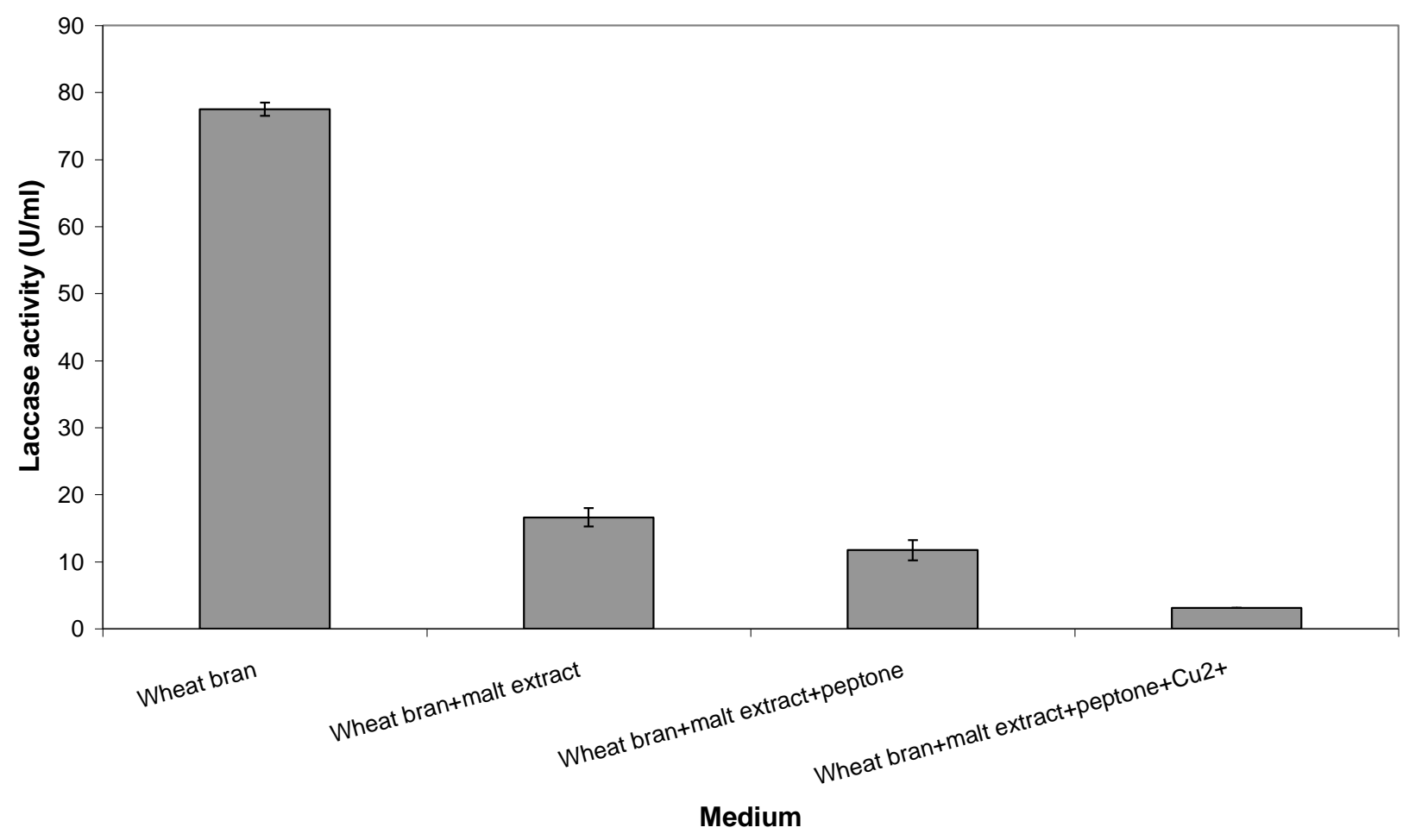

Figure 5: Production of laccase using wheat bran with different additives such as malt extract, peptone, $\mathrm{CuSO}_{4} \cdot 5 \mathrm{H}_{2} \mathrm{O}$.

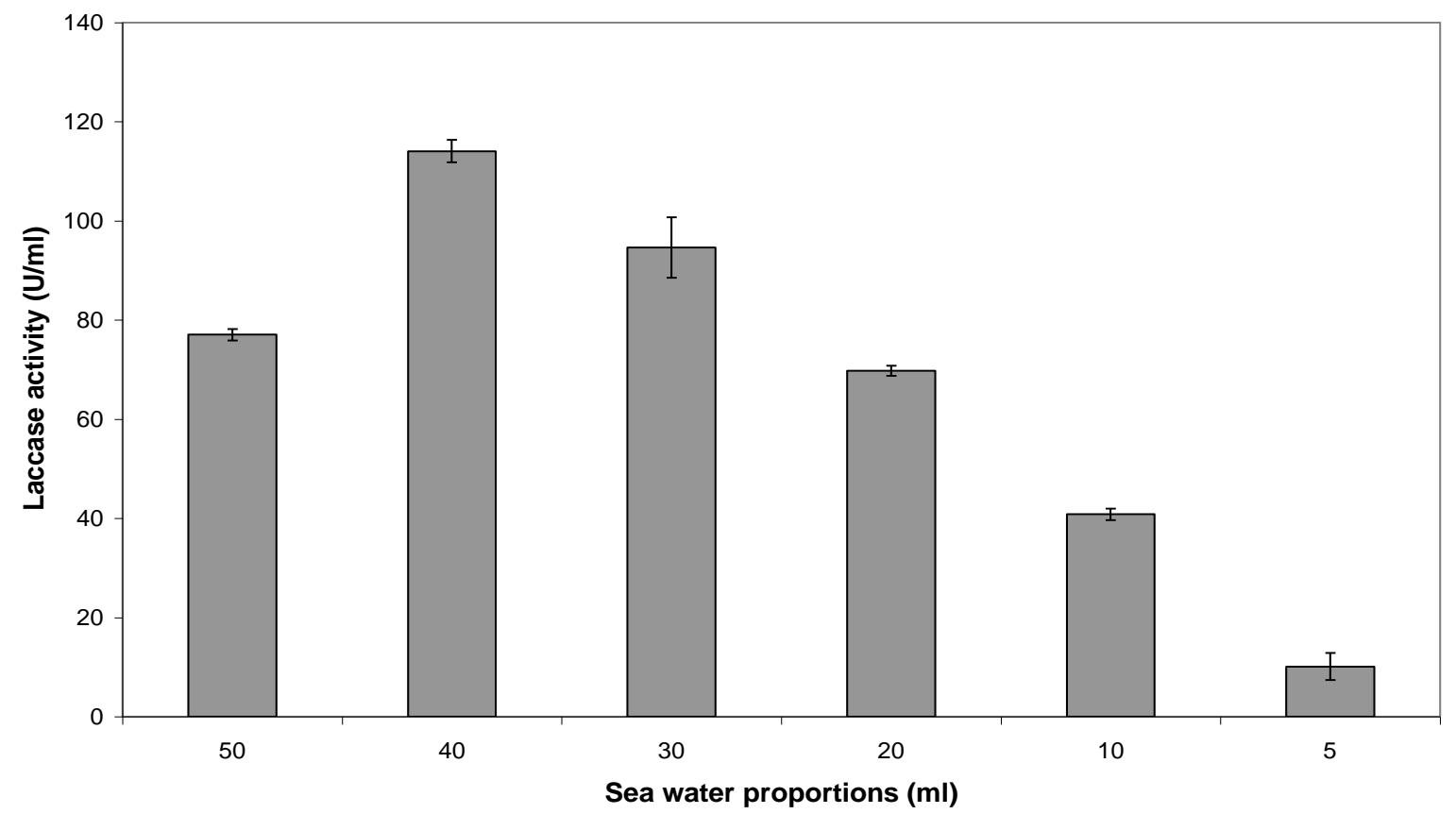

Figure 6: Effect of different sea water proportion on laccase production. 
This may be due to growing the fungus under conditions similar to their natural habitats. Also $A$. alternata produced appreciable level of laccase activity $(94.61 \pm 6.12 \mathrm{U} / \mathrm{mL})$ when the wheat bran prepared with $30 \mathrm{~mL}$ sea water proportion. Rohrmann and Molitoris (1992) indicated that marine basidiomycetes and ascomycetes grown in seawater media showed higher laccase activity than those grown in fresh water media.

\section{Decolourization of synthetic dyes by the marine- derived fungus $A$. alternata in liquid media}

The results indicated that the dyes belonging to different concentrations and chemically different groups were not decolorized to the same extent.

Figure 7 shows the decolorization of 0.01 and $0.05 \%$ Reactive Black (Azo synthetic dye). At the concentration of $0.01 \%$ Reactive Black was decolorized to a very high extent, $50.16 \%$ of the dye was removed after 19 days, and $75.47 \%$ of the dye was removed after 30 days. Mtui and Nakamura (2008) indicated the decolorization of Reactive dyes after 12 days by the marine basidiomycetes fungus Flavodon flavus. Yang et al. (2003) demonastrated significant decolorization of aromatic dyes by terrestrial fungi while Raghukumar et al. (1999; 2004) and Raghukumar (2005) reported the same trends for facultative marine fungi. But at the other concentration of $0.05 \%$ the decolorization reached only about $10.94 \%$ of the dye. The results in Figure 8 indicated that, Malachite Green with the two different concentrations was decolorized only poorly, after 30 days the extents of decolorization were only $9.04 \%$ of the dye at $0.01 \%$ concentration, and $6.07 \%$ of the dye at $0.05 \%$ concentration, the results are consisted with the reports by Eichlerová et al., (2006) who found that the extent of Malachite Green decolorization was only $5 \%$ of the dye after 14 days.

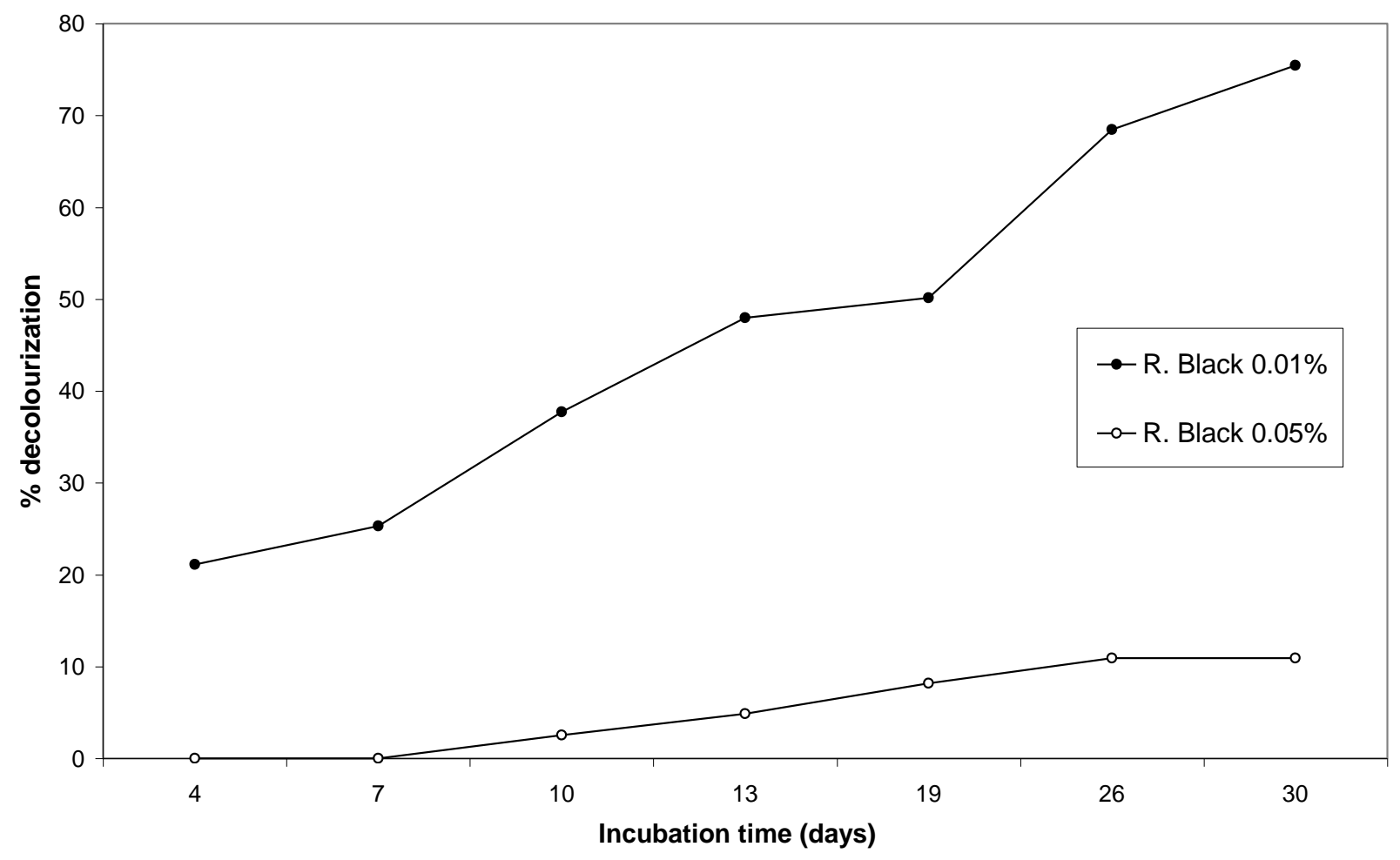

Figure 7: Decolourization of Reactive Black at final concentrations of $0.05 \%$ and $0.01 \%$, by the marine-derived fungus A. alternata cultivated in liquid malt extract.

The pattern of decolorization of Crystal Violet by $A$. alternata is shown in Figure 9. At the concentration 0.01\% Crystal Violet was decolorized quite efficiently, $50.74 \%$ of the dye was removed after 13 days, and $69.35 \%$ of the dye was removed after 30 days. These results higher than that reported by Eichlerová et al. (2006) who found that the extent of Crystal Violet decolorization was only $27 \%$ of the dye after 14 days.

At $0.05 \%$ concentration of Crystal Violet the decolorization was lower $(12.97 \%$ of the dye decolorized after 30 days). Nyanhongo et al. (2002) and Xu (1996) also refer to low triphenylmethane dye decolorization capacity in white rot fungi. 


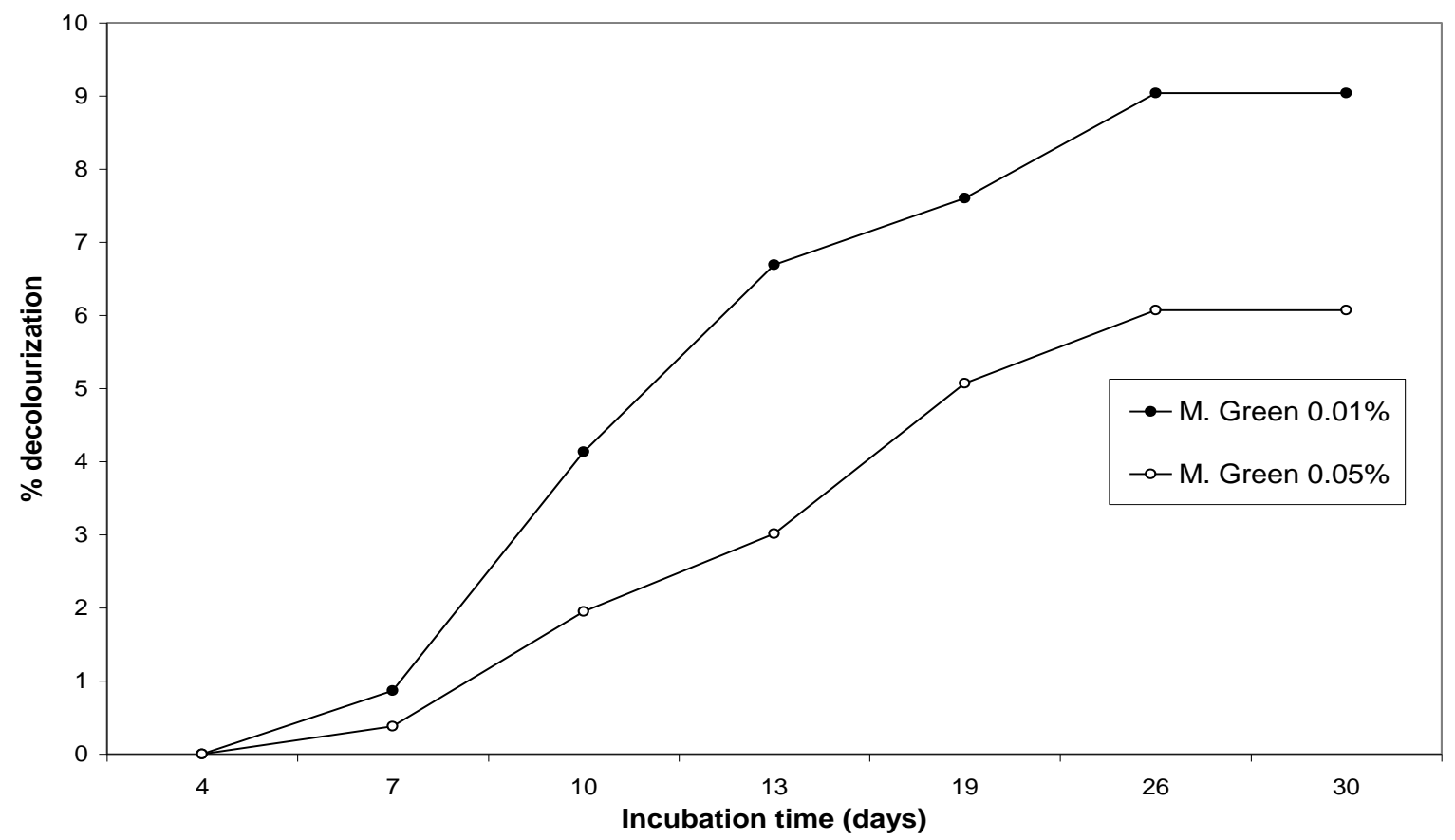

Figure 8: Decolourization of Malachite Green at final concentrations of $0.05 \%$ and $0.01 \%$, by the marine-derived fungus $A$. alternata cultivated in liquid malt extract.

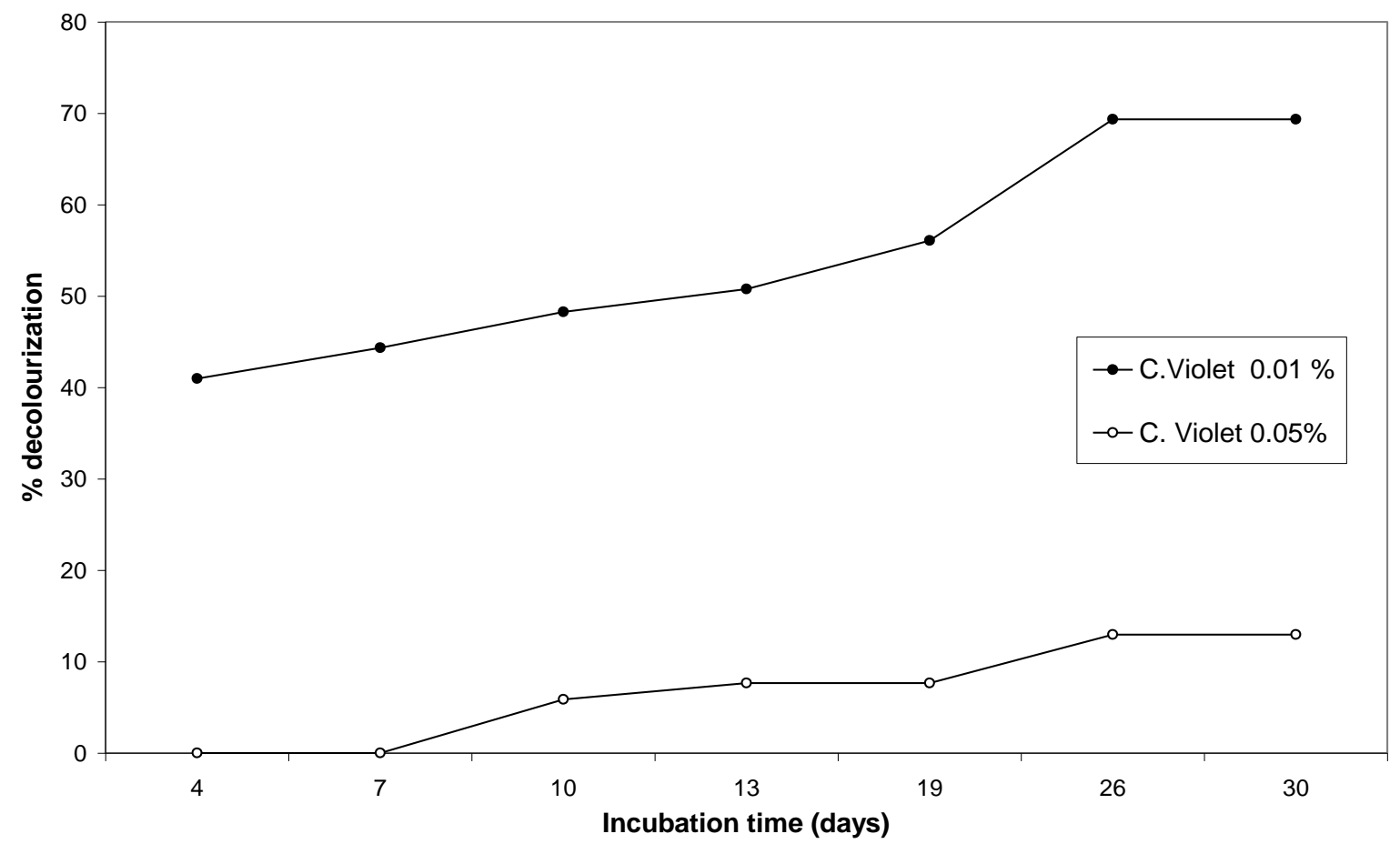

Figure 9: Decolourization of Crystal Violet at final concentrations of $0.05 \%$ and $0.01 \%$ by, the marine-derived fungus $A$. alternata cultivated in liquid malt extract. 


\section{CONCLUSION}

In conclusion, the marine-derived fungus $A$. alternata has the ability to produce appreciable amount of laccase, by using the cheap and easily available agricultural residue wheat bran as unique substrate in submerged fermentation conditions. Our results showed that $A$. alternata was able to decolorize $75.47 \%$ of the synthetic Reactive Black dyes at $0.01 \%$ concentration, after 30 days of incubation. Also has good ability to decolorize about $69.35 \%$ of the dye Crystal Violet, at $0.01 \%$ concentration, after 30 days. Therefore, this strain could be considered a promising source for laccase production, an enzyme that has wide spread industrial applications and can be considered as a great target for future studies related to biotechnological applications and bioremediation in high salt concentration environments.

\section{REFERENCES}

Arora, D. S. and Gill, P. K. (2001). Effects of various media and supplements on laccase production by some white rot fungi. Bioresource Technology 77, 89-91.

Baldrian, P. (2003). Interactions of heavy metals with white-rot fungi. Enzyme and Microbial Technology 32, 78-91.

Bartlett, R. E. (1971). Public Health Engineering-Design in Metric Waste-Water treatment. Applied Science Publishers, London.

Bournnais, R., Paice, M. G., Reid, I. D., Lanthier, P. and Yaguchi, M. (1995). Lignin oxidation by laccase isoenzymes from Trametes versicolor. Applied and Environmental Microbiology 61, 1876-1880.

Bucher, V. V. C., Hyde, K. D., Pointing, S. B. and Reddy, C. A. (2004). Production of wood decay enzymes, mass loss and lignin solubilization in wood by marine ascomycetes and their anamorphs. Fungal Diversity 15, 1-14.

Chinnaraj, A. and Untawale, A. G. (1992). Manglicolous fungi from India. Mahasagar 25, 25-29.

De Souza, C. G. M., Tychanowicz, G. K., De Souza, D. F. and Peralta, R. M. (2004). Production of laccase isoforms by Pleurotous pulmonarius in response to presence of phenolic and aromatic compounds. Journal of Basic Microbiology 44, 129-136.

D’Souza, D. T., Tiwari, R., Sah, A. K. and Raghukumar, C. (2006). Enhanced production of laccase by a marine fungus during treatment of colored effluent and synthetic dyes. Enzyme and Microbial Technology 38, 504-511.

Eichlerová, I., Homolka, L. and Nerud, F. (2006). Ability of industrial dyes decolorization and ligninolytic enzymes production by different Pleurotus species with special attention on Pleuroutus calyptratus, strain CCBAS 461. Process Biochemistry 41, 941-946.
Galhaup, C. and Haltrich, D. (2001). Enhanced formation of laccase activity by the white-rot fungus Trametes pubescens in the presence of copper. Applied Microbiology and Biotechnology 56, 225-232.

Galhaup, C., Wagnera, H., Hinterstoisser, B. and Haltrich, D. (2002). Increased production of laccase by the wood-degrading basidiomycete Trametes pubescens. Enzyme and Microbial Technology 30, 529-536.

Galliano, H. G., Gas, J., Seris, L. and Boudet, A. M. (1991). Lignin degradation by Rigidoporus lignosus involves synergistic action of two oxidizing enzymes: Mn peroxidase and laccase. Enzyme and Microbial Technology 13, 478-482.

Höller, U., König, G. M. and Wright, A. D. (1999). A new tyrosin kinase inhibitor from a marine isolate of Ulocladium botrytis and new metabolites from the marine fungi Asteromyces cruciatus and Varicosporina ramulosa. European Journal of Organic Chemistry 11, 2949-2955.

Kohlmeyer, J. and Kohlmeyer, B. V. (1991). Illustrated key to the filamentous higher marine fungi. Botanica Marina 34, 1-61.

Leonowicz, A., Cho, N. S., Luterek, J., Wilkolazka, A., Wotjas-Wasilewska, M., Matuszewska, A., Hofrichter, M., Wesenberg, D. and Rogalski, J. (2001). Fungal laccase: Properties and activity on lignin. Journal of Basic Microbiology 41, 185227.

Levin, L., Ramos, A. M. and Forchiassin, F. (2002). Copper induction of lignin modifying enzymes in the whiteb rot fungus Trametes trogii. Mycologia 94, 377-383.

Levin, L., Herrmann, C., and Papinutti, V. L. (2008). Optimization of lignocellulolytic enzyme production by the white-rot fungus Trametes trogii in solid-state fermentation using response surface methodology. Biochemical Engineering Journal 39, 207-214.

Majeau, J. A., Brar, S. K. and Tyagi, R. D. (2010). Laccases for removal of recalcitrant and emerging pollutants. Bioresource Technology 101, 2331-2350.

Maltseva, O. V., Niku-Paavola, M. L., Leontievsky, A. A., Myasoedova, N. M. and Golovleva. L. A. (1991). Ligninolytic enzymes of the white rot fungus Panus tigrinus. Biotechnology and Applied Biochemistry 13, 291-302.

Mtui, G. and Masalu, R. (2008). Extracellular enzymes from brown-rot fungus Laetiporus sulphureus isolated from mangrove forests of coastal Tanzania. Academic Journals 3 (4), 154-161.

Mtui, G. and Nakamura, Y. (2008). Lignocellulosic enzymes from Flavodon flavus, a fungus isolated from Western Indian Ocean off the coast of Dar es Salaam, Tanzania. African Journal of Biotechnology 7 (17), 3066-3072.

Newell, S. Y. (1993). Decomposition of shoots of a saltmarsh grass, Methodology and dynamics of 
microbial assemblages. Advanced Microbial Ecology 13, 301-326.

Nilsson, T., Daniel, J., Kirk, T. K. and Obst, J. R. (1989). Chemistry and microscopy of wood decay by some higher ascomycetes. Holzforschung 43, 11-18.

Nyanhongo, G. S., Gomes, J., Gübitz, G., Zvauya, R., Read, J. S. and Steiner, W. (2002). Decolorization of textile dyes by laccases from a newly isolated strain of Trametes modesta. Water Research 36, 1449-1456.

Okino, L. K., Machado, K. M. G., Fabric, C. and Bonomi, V. L. R. (2000). Ligninolytic activity of tropical rainforest basidiomycetes. World Journal of Microbiology and Biotechnology 16, 889-893.

Palmieri, G., Giardiana, P., Bianco, C., Fontanella, B. and Sannia, G. (2000). Copper induction of laccase isoenzymes in the ligninolytic fungus Pleurotus ostreatus. Applied and Environmental Microbiology 66, 920-924.

Pitt, J. I. and Hocking, A. D. (1985). Fungi and Food Spoilage. Academic Press (Pub.) Sydney, New York, London.

Pointing, S. B. and Hyde, K. D. (2000). Lignocellulosedegrading marine fungi. Biofouling 15, 221-229.

Pointing, S. B., Vrijmoed, L. L. P. and Jones, E. B. G. (1998). A qualitative assessment of lignocellulose degrading activity in marine fungi. Botanica Marina 41, 290-298.

Raghukumar, C. (2005). Marine fungi and their enzymes for decolorization of coloured effluents. In: Marine Lignolytic Fungi. Ramiah, N. (ed). National Institute of Oceanography, GOA pp. 145-158.

Raghukumar, C., Mohandass, C., Kamat, S. and Shailaja, M. S. (2004). Simultaneous detoxification and decolorization of molasses spent wash by the immobilized white-rot fungus Flavodon flavus isolated from a marine habitat. Enzyme and Microbial Technology 35, 197-202.

Raghukumar, C., D'Souza, T. M., Thorn, R. G. and Reddy, C. A. (1999). Lignin-modifying enzymes of Flavodon flavus, a basidiomycete isolated from a coastal marine environment. Applied and Environmental Microbiology 65, 2103-2111.

Raghukumar, S., Sathe-Pathak, V., Sharma, S. and Raghukumar, C. (1995). Thraustochytrid and fungal component of marine detritus. III. Field studies on decomposition of leaves of the mangrove Rhizophora apiculata. Aquatic Microbial Ecology 9, 117-125.

Robles, A., Lucas, R., Martínez-Cañamero, M., Omar, N. B., Pérez, R. and Gálvez, A. (2002). Characterisation of laccase activity produced by the hyphomycete Chalara (syn. Thielaviopsis) paradoxa $\mathrm{CH} 32$. Enzyme and Microbial Technology 31, 516-522

Rohrmann, S. and Molitoris, P. (1992). Screening of wood-degrading enzymes in marine fungi. Canadian Journal of Botany 70, 2116-2123.

Sathe, V. and Raghukumar, S. (1991). Fungi and their biomass in detritus of the seagrass Thalassia Hemprichii (Eherenberg) Ascherson. Botanica Marina 34, 271-277.

Vishwakiran, Y., Thakur, N. L., Raghukumar, S., Yennawar, P. L. and Anil, A. C. (2001). Spatial and temporal distribution of fungi and wood borers in the coastal tropical waters of Goa, India. Botanica Marina 44, 47-56.

Vrijmoed, L. L. P. and Tan, N. F. Y. (1990). Fungi associated with leaves of Kandelia candel (L.) Druce in litter bags on the mangrove floor of a subtropical mangrove community in Hong Kong. Bulletin of Marine Science 47, 261-267.

Xu, F. (1996). Oxidation of phenols, anilines and benzenethiols by fungal laccases: Correlation between activity and redox potentials as well as halide inhibition. Biochemistry 35, 7608-7614.

Yang, Q. Y., Yang, M., Pritsch, K., Yediler, A., Hagn, A., Scloter, M. and Kettrup, A. (2003). Decolorization of synthetic dyes and production of manganese-dependent peroxidases by new fungal isolates. Biotechnology Letters 25, 501713. 